\title{
Trk C Signaling Is Required for Retinal Progenitor Cell Proliferation
}

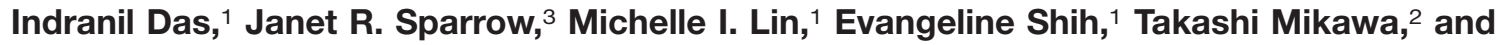 \\ Barbara L. Hempstead 1
}

Departments of ${ }^{1}$ Medicine and ${ }^{2}$ Cell Biology, Weill Medical College of Cornell University, New York, New York 10021, and ${ }^{3}$ Columbia University, Department of Ophthalmology, New York, New York 10032

\begin{abstract}
Although neurotrophin actions in the survival of specific retinal cell types have been identified, the biological functions for neurotrophin-3 (NT-3) in early retinal development remain unclear. Having localized NT-3 and trk C expression at early developmental stages when retinal neuroepithelial progenitor cells predominate, we sought to modulate NT-3 signaling in these cells by overexpressing a truncated isoform of the NT-3 receptor, trk $\mathrm{C}$. We have demonstrated that this non-catalytic receptor can inhibit NT-3 signaling when coexpressed with the full-length kinase-active trk $C$ receptor. Using a replicationdeficient retrovirus to ectopically express the truncated trk $\mathrm{C}$ receptor to limited numbers of progenitor cells in ovo, we examined the effects of disrupted trk $\mathrm{C}$ signaling on the proliferation or differentiation of retinal cells. Clones expressing trun-
\end{abstract}

cated trk $\mathrm{C}$ exhibited a $70 \%$ reduction in clone size, compared with clones infected with a control virus, indicating that inhibition of trk $\mathrm{C}$ signaling decreased the clonal expansion of cells derived from a single retinal progenitor cell. Additionally, impaired NT-3 signaling resulted in a reduction of all retinal cell types, suggesting that NT-3 targets retinal precursor cells rather than differentiated cell types. BrdU labeling studies performed at E6 indicate that this reduction in cell number occurs through a decrease in cell proliferation. These studies suggest that NT-3 is an important mitogen early in retinal development and serves to establish the size of the progenitor pool from which all future differentiated cells arise.

Key words: retina; NT-3; trk C; truncated trk C; retrovirus; chick; mitogen
During retinal development, multipotent progenitor cells in the neuroepithelium undergo commitment and differentiation to yield all of the cell types of the retina (Holt et al., 1988; Turner et al., 1990). Retinal progenitors become progressively restricted in the cell types they can generate, and the time at which a retinal precursor commits correlates with the cell type to which it differentiates (Lillien, 1994; Cepko et al., 1996). Because progenitor cells in the retina remain mitotically active during embryonic and, in some species, early postnatal development, it is important to define the factors regulating progenitor cell proliferation. In in vitro studies, transforming growth factor (TGF)- $\alpha$ and TGF- $\beta 3$, epidermal growth factor (EGF), and basic fibroblast growth factor (bFGF) and acidic FGF (aFGF) promote progenitor cell proliferation at different periods of retinal development in rodent (Anchan et al., 1991; Lillien and Cepko, 1992; Anchan and Reh, 1995), whereas insulin and insulin-like growth factor (IGF)-I and IGF-II induce proliferation in fish and chick retinal cultures (Hernandez-Sanchez et al., 1995; Boucher and Hitchcock, 1998). The utilization of different mitogenic growth factors at distinct periods of retinal histogenesis suggests that the coordinate action of several growth factors may regulate the proliferation of neuroepithelial cells in the retina (Lillien and Cepko, 1992; Anchan

\footnotetext{
Received Oct. 7, 1999; revised Jan. 28, 2000; accepted Feb. 4, 2000.

These studies were supported by Public Health Service Grants NS30687 and HL58130 to B.L.H, EY12293 to J.R.S., HL62175, HL56987, and HL54128 to T.M., and EY07138. We thank Dr. Judith Hirsh for assistance with Camera Lucida techniques, Dr. Donna Fekete for early assistance in chick injections, Dr. Pantelis Tsoulfas for reagents, Dr. Doris Herzlinger for access to her histology facility, and Greg Schwartz and Dr. Meeghan Sinclair for their technical assistance. We also thank Dr. Jeanette Hyer and Dr. Tomoko Obara-Ishihara for their technical advice and expertise.

Correspondence should be addressed to Barbara L. Hempstead, Department of Medicine, Room C606, Weill Medical College of Cornell University, 1300 York Avenue, New York, NY 10021. E-mail: blhempst@mail.med.cornell.edu. Copyright (C) 2000 Society for Neuroscience $0270-6474 / 00 / 202887-09 \$ 15.00 / 0$
}

and Reh, 1995). Because the degree of proliferation in explant cultures induced by exogenous factors is less than that detected in vivo, other mitogenic factors may exist, some of which could be derived from adjacent tissues such as the retinal pigmented epithelium (Lillien and Cepko, 1992).

Neurotrophin-3 (NT-3) is a member of the neurotrophin family and regulates the development of neurons in the CNS and PNS that express the receptor tyrosine kinase trk C (Davies, 1994; Lewin and Barde, 1996). After NT-3 binding, trk C undergoes kinase activation, leading to the recruitment and phosphorylation of signaling proteins that regulate neuronal proliferation, differentiation, and survival. In addition, alternative splicing of the trk $\mathrm{C}$ gene can generate truncated trk $\mathrm{C}$ isoforms that lack the kinase domain (Tsoulfas et al., 1993; Valenzuela et al., 1993; Garner and Large, 1994; Menn et al., 1998). The non-catalytic receptors, which are well conserved among species, may sequester neurotrophins and inhibit signaling by catalytic receptors when both catalytic and truncated isoforms are coexpressed. Indeed, overexpression of truncated trk $\mathrm{C}$ in a transgenic mouse model results in a phenotype similar to that observed in trk C or NT-3 null mutant animals, suggesting that truncated trk $\mathrm{C}$ receptors negatively modulate kinase-active trk C signaling (Palko et al., 1999).

NT-3 and trk C are expressed in the developing chick retina as early as embryonic day 5 (E5) (Bovolenta et al., 1996), and their expression persists through hatching (Bovolenta et al., 1996; Hallbook et al., 1996; Das et al., 1997). At later developmental stages, NT-3 production by retinal amacrine and ganglion cells (GCs) may serve important trophic actions on central retinal targets (von Bartheld et al., 1996a, 1996b). However, the coexpression of NT-3 and trk C in retina before target innervation suggests that NT-3 might serve additional local actions in retina (Hallbook et al., 1996; Das et al., 1997; Herzog and von Bartheld, 
1998). NT-3 promotes the survival and differentiation of retinal cells in vitro (de la Rosa et al., 1994a). Additionally, antibodymediated NT-3 depletion at E3 in ovo results in a reduction in the number of ganglion cells, narrowing of the retinal lamina, and disrupted synaptic organization (Bovolenta et al., 1996). At later developmental stages (E9-E13) NT-3 promotes the survival of retinal amacrine and ganglion cells in vitro, suggesting that NT-3 may exert pleotropic functions at different developmental stages. However, the direct actions of NT-3 on trk C-expressing cells in early retinal development remains to be clearly defined.

Thus, to more precisely define the role of NT-3 in early retinal development, we have used retroviral gene delivery to alter NT-3 signaling. Replication-deficient recombinant retrovirus encoding the chicken truncated trk $\mathrm{C}$ receptor was delivered to the developing retina to inhibit NT-3-dependent trk C activation. Using clonal analysis, these in vivo studies have allowed us to assess the effects of impaired NT-3 signaling on retinal progenitor cell proliferation, differentiation, and migration.

\section{MATERIALS AND METHODS}

Tissue preparation and NT-3 immunohistochemical staining. Fertilized eggs from White Leghorn chickens (Truslow Farms, Chestertown, MD) were incubated as described (Das et al., 1997). Embryos harvested at E5 were fixed in $0.1 \%$ paraformaldehyde in PBS for $1 \mathrm{hr}$ and cryoprotected, and the posterior retina was sectioned on a cryostat $(10 \mu \mathrm{m})$. Tissue sections were blocked in $5 \%$ goat serum containing $0.1 \%$ Triton X-100, then incubated with an antibody to NT-3 (1:200) (Santa Cruz Biotechnology, Santa Cruz, CA). Immunoreactivity was visualized by the biotinavidin immunoperoxidase method (Vectastain Elite ABC Kit, Vector Laboratories, Burlingame, CA) using a VIP substrate (Vector Laboratories) and counterstained with hematoxylin. The specificity of the immunoreactivity was confirmed by preadsorbing the primary antibody with the NT-3 immunizing peptide (Santa Cruz) and has been confirmed by the lack of immunoreactivity on tissues from NT-3 (-/-) null mutant mice.

RT-PCR of full-length trk C. Eyes were isolated from E5 embryos, minced, and triturated with 18 and 22 gauge needles. RNA was isolated according to the procedure described by Chomczynski and Sacchi (1987). The RNA samples were reverse-transcribed using random hexamers according to the protocol of the GeneAmp RNA PCR kit (Perkin-Elmer, Norwalk, CT). Samples incubated in the absence of reverse transcriptase were used as a negative control. The reaction conditions and specific primers used for PCR amplification of full-length trk $\mathrm{C}$ were described previously (Henion et al., 1995). The PCR products were separated on a $7 \%$ acrylamide gel and stained with ethidium bromide.

Generation of recombinant replication-deficient retrovirus. The chick truncated trk C cDNA was a kind gift of Pantelis Tsoulfas (The Miami Project, University of Miami) and corresponds to the published sequence designated as the kinase deleted trk C by Garner and Large (1994). The coding region of truncated trk $\mathrm{C}$ beginning at $-15 \mathrm{bp}$ of the $5^{\prime} \mathrm{UTR}$ and including $7 \mathrm{bp}$ of the $3^{\prime}$ UTR was subcloned into the SMA site of the pCXIZ replication-deficient retroviral vector that encodes the lacZ gene (Mikawa, 1995). This viral construct expresses a dicistronic message under the transcriptional control of the viral LTR and uses an internal ribosome entry site (IRES) sequence to direct the translation of $\beta$-galactosidase $(\beta$-gal). After cotransfection with the viral DNA and pMEX $^{\text {neo }}$ plasmid into the D17.2G packaging cell line (Mikawa et al., 1991), stable clones yielding infective titers of $>10^{4} / \mathrm{ml}$ were isolated by repetitive subcloning (four times) and propagated as previously described (Mikawa et al., 1991). For in ovo injections, virus was harvested from nearly confluent monolayers and concentrated by centrifugation. The retrovirus produced by these clones was confirmed to be replicationdeficient by methods described by Mikawa et al. (1991). Control virus (CXL) encoding $\beta$-galactosidase was used as a control (Mikawa et al., 1991).

NT-3 cross-linking analysis to demonstrate truncated trk $C$ expression in retroviral lines. NT-3 (human recombinant; Promega, Madison, WI) was radio-iodinated using lactoperoxidase as described (Hempstead et al., 1989) to a specific activity of $2500 \mathrm{cpm} / \mathrm{fmol}$. The D17.2G-expressing truncated trk C (truncC) or parental D17.2G cells suspended at $1 \times 10^{6}$ cells $/ \mathrm{ml}$ were incubated with $50 \mathrm{ng} / \mathrm{ml}{ }^{125} \mathrm{I}-\mathrm{NT}-3$ for $2 \mathrm{hr}$ at $4^{\circ} \mathrm{C}$ as described (Kaplan et al., 1991). Bound NT-3 was cross-linked to cells by exposure to $50 \mathrm{~mm} n$-hydroxy-succinimidyl-4-azido benzoate (HSAB) (Pierce, Rockford, IL) for $10 \mathrm{~min}$ with photoactivation using a $365 \mathrm{~nm}$ UV lamp. Cells were washed twice in $50 \mathrm{~mm}$ lysine in PBS to quench the $\mathrm{HSAB}$, and lysed in RIPA buffer containing protease inhibitors. Proteins were separated by SDS-PAGE, and autoradiography was performed as described (Hempstead et al., 1991).

Cell transfection and Western blot analysis. The D17.2G packaging cell line or truncC line was transiently transfected with pCDNA3 encoding kinase-active rat trk $\mathrm{C}$ using lipofectamine. Forty-eight hours after transfection, cells were washed and incubated in serum-free media for $2 \mathrm{hr}$, followed by treatment with or without $50 \mathrm{ng} / \mathrm{ml} \mathrm{NT}-3$ for $5 \mathrm{~min}$. Cells were lysed in RIPA buffer containing protease and phosphatase inhibitors, and kinase-active trk receptors were immunoprecipitated using anti-trk antisera (Kaplan et al., 1991; Hempstead et al., 1992) that recognizes kinase-active trk $\mathrm{A}, \mathrm{B}$, and $\mathrm{C}$. Immunoprecipitates were separated by SDS-PAGE, and Western blot analysis was performed using the anti-trk antisera or an anti-phosphotyrosine antibody (4G10; Upstate Biotechnology, Lake Placid, NY). Truncated trk $\mathrm{C}$ was detected using an antibody specific for a unique 16 amino acid sequence in the cytoplasmic tail of chick truncated trk C (LNPISLPGHSKPLNQG) corresponding to an antibody previously characterized (Donovan et al., 1995). PC12 cells overexpressing trk A (615) were used as positive control for trk expression and phosphorylation.

Injection of retrovirus. Fertilized eggs were incubated to E2.5-E3 (stage 13-16) (Hamburger and Hamilton, 1992), and a small hole was created around the top of the egg and in the vitelline membrane overlying the eye. Using a glass micropipette mounted in a micromanipulator, $10-20 \mathrm{nl}$ of concentrated virus was delivered into the subretinal space by pressure injection (Picospritzer II; General Valve Corporation, Fairfield, NJ). The egg shell was then sealed with parafilm and incubated for 3-12 d as indicated. All procedures were approved by the Institutional Animal Care Committee of Weill Medical College.

Processing of embryos. Embryos were harvested (E9 or E15) and decapitated, and the injected eye was excised. The eye cup was fixed in $2 \%$ PFA in PBS for $1 \mathrm{hr}$, washed with PBS, and treated with the chromogenic substrate 5-bromo-4-chloro-3-indolyl- $\beta$-D-galactoside (X-gal) to detect $\beta$-gal-expressing cells. The position of clones in whole-mount preparations of retina was recorded relative to the tip of the optic nerve head using a micrometer grid. Clones within the central retina were identified at E15 as a $4 \mathrm{~mm}^{2}$ area and at E9 as a $2.25 \mathrm{~mm}^{2}$ area, extending inferiorly from the tip of the optic nerve head to a point $4 \mathrm{~mm}$ (E15 retina) or $3 \mathrm{~mm}$ (E9 retina) superiorly, and $2 \mathrm{~mm}$ (E15) or $1.5 \mathrm{~mm}$ (E9) to the nasal and temporal side of the optic nerve head. Tissues were embedded in paraffin and serially sectioned at $10 \mu \mathrm{m}$.

Immunofluorescence detection of truncated trk $C$ and $\beta$-galactosidase. Embryos injected at E2.5 with truncC expressing retrovirus were killed at E7, and eyes were fixed, cryoprotected, and sectioned at $10 \mu \mathrm{m}$. Sections were permeabilized in $0.1 \%$ Triton X-100 for $30 \mathrm{~min}$, and double immunohistochemical labeling was performed using the polyclonal antisera recognizing truncated trk $\mathrm{C}(1: 500)$ and a monoclonal antibody to $\beta$-galactosidase (1:500; Sigma, St. Louis, MO). After washing, sections were incubated in FITC-conjugated horse anti-mouse IgG (1:200; Jackson ImmunoResearch Laboratories, West Grove, PA) and Texas Redconjugated goat anti-rabbit IgG (1:200; Jackson Labs), washed, and examined using a Nikon epifluorescence microscope.

$B r d U$ labeling in ovo. Chick embryos injected at E2.5 were administered the thymidine analog bromodeoxyuridine (BrdU) (75 $\mu \mathrm{g}$; Amersham, Arlington Heights, IL) at E6 by administration onto the chorioallantoic membrane for $4 \mathrm{hr}$ before they were killed. After fixation and incubation with X-gal substrate, eyes with central retinal infections were embedded in paraffin and sectioned at $10 \mu \mathrm{m}$. BrdU histochemistry using anti-BrdU antibody (1:500; Dako, Glostrup, Denmark) was performed after quenching of endogenous peroxidase using $0.1 \%$ hydrogen peroxide in methanol $\left(-20^{\circ} \mathrm{C}\right)$, permeabilization with proteinase $\mathrm{K}$, treatment in $2 \mathrm{~N} \mathrm{HCl}$, and neutralization in $0.1 \mathrm{~m}$ Borax, $\mathrm{pH} 9.6$, as per the commercial protocol. Immune complexes were visualized using biotinylated horse anti-mouse $\operatorname{IgG}$ (Vector Laboratories) and the Vectastain Elite ABC Kit using a VIP substrate (Vector Laboratories).

Clonal analysis. X-gal-stained sections of retrovirally infected retina were analyzed using a computer-assisted three-dimensional reconstruction system (Neurolucida, MicrobrightField Inc., Colchester, VT). Microscopic and computer graphics images were superimposed through the oculars of the microscope using a drawing tube and attached miniature monitor (Lucivid, MicrobrightField Inc.). Multiple computer-generated 

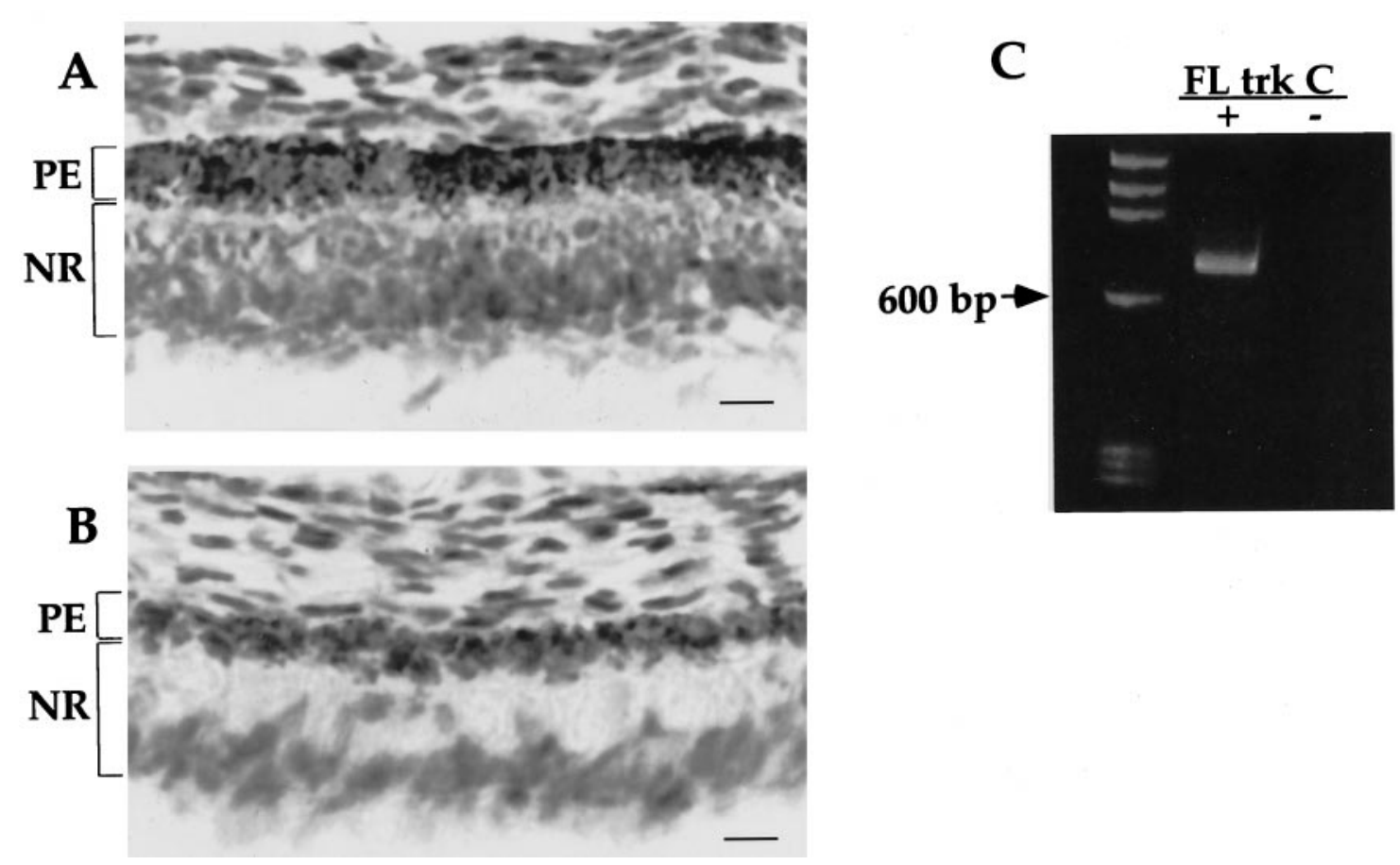

Figure 1. Expression of NT-3 and trk C receptors in E5 chick eye. $A$, E5 frozen sections were immunostained with antisera to NT-3 using a VIP chromogenic substrate (red) and counterstained with hematoxylin (blue). Labeling for NT-3 is most prominent adjacent to the retinal pigment epithelium in an area of retina where retinal progenitors are mitotically active. Labeling is also detected in the innermost retina. $P E$, Pigmented epithelium; $N R$, neural retina. $B$, In the control section, labeling was blocked by addition of immunizing peptide. Scale bar, $10 \mu \mathrm{m}$. $C$, Total RNA from chick eyes harvested at E5 was subjected to RT-PCR using primers specific for full-length trk C. - and + indicate the absence and presence, respectively, of reverse transcriptase during cDNA synthesis as a control for genomic DNA contamination. The full-length trk C primers generated a single band of the expected molecular size (772 bp).

markers and rulers made it possible to label cell types and take measurements within the microscopic image. Retinal clone size was determined at E15 by counting $\beta$-galactosidase-positive cells in single clones on serial sections using a $100 \times$ objective. In addition, the cell type composition of individual clones was determined on the basis of cell morphologies and the positions of the cells within retinal lamina (Fisher, 1979; Fekete et al., 1994).

For analysis of retinal clone size at E9, individual cells could not be accurately counted so clone size was determined on the basis of clonal volume. Serial sections were viewed through a $40 \times$ objective, and cellular regions containing the $\beta$-gal-positive blue precipitate were delineated, with area measurements determined using the Neurolucida program. Clonal volume was calculated as the sum of the areas occupied by $\beta$-gal-stained cells in each section multiplied by section thickness.

BrdU analysis. To determine the number of BrdU-labeled nuclei in $\beta$-gal-labeled clones of E6 retina, $\mathrm{BrdU}^{+}$nuclei were counted, and the $\beta$-gal-positive areas were determined as described above. Quantitative analyses were restricted to central retina, and to further control for proliferation gradients we used clones that were position-matched between truncated trk $\mathrm{C}$-infected and CXL-infected retinas. Numbers of $\mathrm{BrdU}^{+}$nuclei were expressed per unit area $\left(\mathrm{mm}^{2}\right)$ rather than per clone to control for the differences in clone size. As an internal control, $\mathrm{BrdU}^{+}$ nuclei were also counted in uninfected ( $\beta$-gal-negative) areas matched by size and shape to the immediately adjacent virally infected areas. The data were normalized as the ratio of BrdU nuclei in $\beta$-gal-positive areas to $\mathrm{BrdU}$ nuclei in $\beta$-gal-negative areas. This ratio represents the number of proliferating cells in the transgene-expressing areas relative to the surrounding noninfected areas.

\section{RESULTS}

\section{Expression of NT-3 and trk C during early chick retinal development}

To determine whether NT-3 could regulate early stages of retinal development, immunolocalization was performed on E5 retinas. NT-3 was detectable in the outermost retina immediately adja- cent to the pigmented epithelium (Fig. $1 A$ ), an area that is part of the neuroblastic region in which retinal progenitors are actively dividing at this stage of development. Additionally, NT-3 immunolabeling was observed in cells of the innermost retina in the developing ganglion cell layer, a region of retina that continues to express NT-3 throughout chick embryonic development (Das et al., 1997). There was an absence of labeling in control sections in which NT-3 antisera was preabsorbed with the immunizing peptide (Fig. 1B). Trk C receptor expression in E5 chick eye was assessed by RT-PCR using primers specific for full-length trk C. Consistent with previous in situ hybridization studies (Bovolenta et al., 1996), trk C mRNA expression was detectable in chick retina at E5 (Fig. 1C). Thus coexpression of NT-3 and trk C was observed at early developmental stages during which progenitor cells predominate.

\section{Generation of a stable truncated trk C viral-producing line}

To assess the role of NT-3 in modulating the early stages of chick retinal development in ovo, a replication-defective retrovirus encoding truncated chick trk $\mathrm{C}$ was generated. Transfection of this viral vector encoding lacZ into a packaging cell line resulted in stable clones from which the virus was propagated at high titer. Expression of truncated trk $\mathrm{C}$ in these clones was confirmed by Western blot analysis, which demonstrated a single $100 \mathrm{kDa}$ band corresponding to the predicted molecular size of truncated trk $\mathrm{C}$ and was absent in blots of parental packaging cells (Fig. 2A,B). To confirm that truncated trk $\mathrm{C}$ expressed by these clones was capable of binding NT-3, cross-linking analysis was performed using the radio-iodinated ligand. The cross-linked product of 


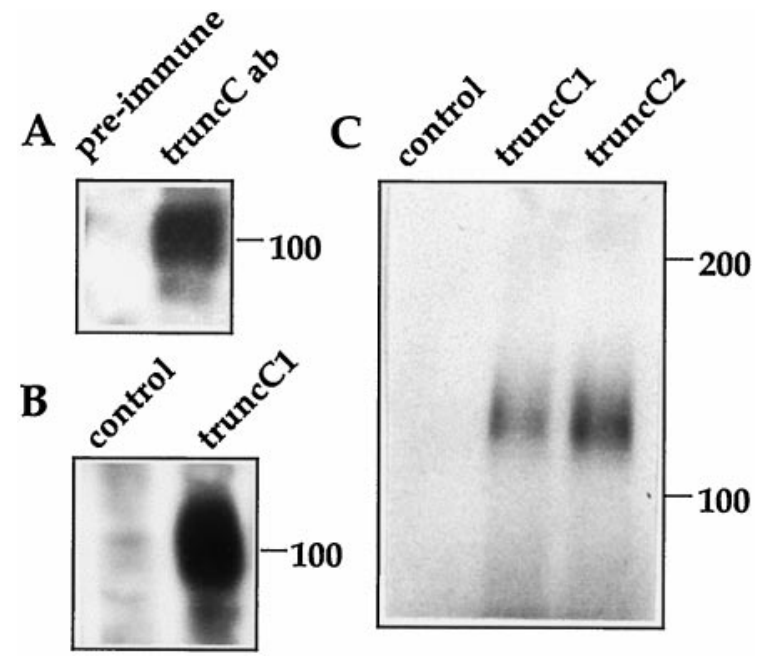

Figure 2. Expression of truncated trk $\mathrm{C}$ by the transfected packaging cell line. $A$, Lysates of truncated trk $\mathrm{C}$ (truncC)-expressing packaging cells were immunoprecipitated with preimmune or immune antisera to truncated trk $\mathrm{C}$, and Western blots were probed with immune antisera to truncated trk C. $B$, Western blots of cell lysates of parental (control) or truncated trk $\mathrm{C}$-expressing packaging cells were probed with the truncated trk $\mathrm{C}$ antisera. Expression of the truncated trk $\mathrm{C}$ receptor was observed at $100 \mathrm{kDa}$. $C$, NT-3 binding to truncated trk $\mathrm{C}$ was detected by cross-linking. Two independent lines stably expressing truncated trk $\mathrm{C}$ and the control parent cell line were incubated with ${ }^{125}$ I-NT-3 after which bound NT-3 was cross-linked to cells using HSAB. After detergent lysis, proteins were separated by SDS-PAGE, and autoradiography was performed. The molecular size of the $125 \mathrm{kDa}$ cross-linked species is consistent with the predicted molecular weight of the NT-3-truncated trk C product $(13+110 \mathrm{kDa})$.

$\sim 125 \mathrm{kDa}$, composed of NT-3 (13.5 kDa) and truncated trk C $(110 \mathrm{kDa})$, was detected in clones expressing the truncated trk $\mathrm{C}$ retrovirus but not in parental packaging cells.

\section{Expression of truncated trk $\mathbf{C}$ inhibits NT-3-mediated kinase-active trk $\mathbf{C}$ activation}

Although studies have demonstrated that the kinase-inactive truncated trk B receptor can inhibit BDNF signaling when coexpressed with kinase-active trk B (Biffo et al., 1995; Eide et al., 1996), the ability of truncated trk $C$ to inhibit kinase-active trk $C$ autophosphorylation has not been formally documented. Thus, kinase-active trk $\mathrm{C}$ was transiently expressed in parental packaging lines or in truncated trk $\mathrm{C}$-expressing clones. After treatment with NT-3 for $5 \mathrm{~min}$, cells expressing only the kinase-active trk C receptor exhibited a robust NT-3-induced trk C autophosphorylation (Fig. 3C). Conversely, cells coexpressing truncated trk $\mathrm{C}$ and full-length trk $\mathrm{C}$ were markedly reduced in the ability of NT-3 to initiate the autophosphorylation of the kinase-active trk C. Expression of truncated trk $\mathrm{C}$ and kinase-active trk $\mathrm{C}$ in each condition was confirmed by immunoblotting (Fig. $3 A, B$ ). Thus, overexpression of truncated trk $\mathrm{C}$ can inhibit NT-3 activation by kinase-active trk $\mathrm{C}$ when both receptor isoforms are coexpressed.

\section{Retrovirally transduced coexpression of truncated trk $\mathbf{C}$ and $\boldsymbol{\beta}$-galactosidase}

For analysis of the effects of truncated trk $\mathrm{C}$ overexpression, in ovo injections were performed in which concentrated viral supernatant from the truncated trk $\mathrm{C}$ packaging clones was introduced into the subretinal space of chick embryos. After retroviral infection and integration into the host genome, the transgenes encoding truncated trk $\mathrm{C}$ and the reporter gene, $\beta$-galactosidase,

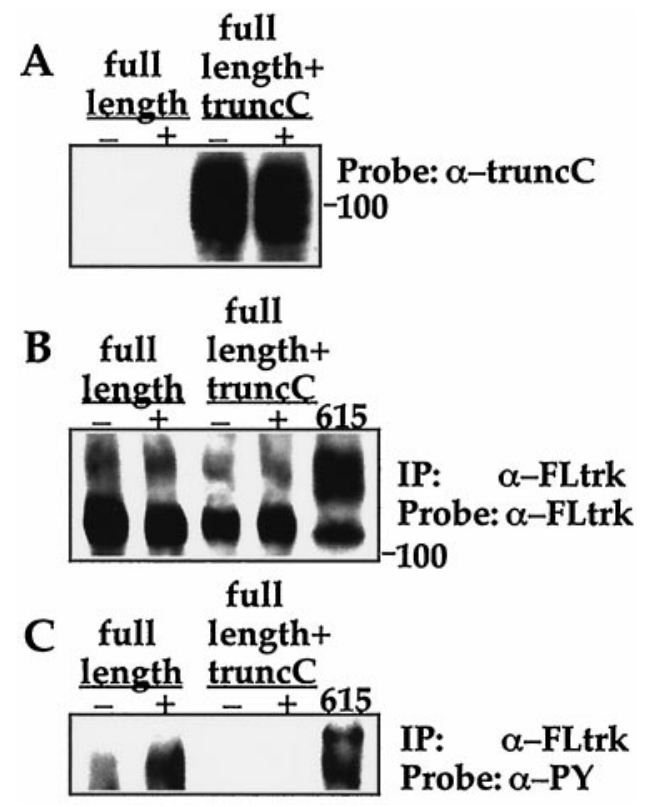

Figure 3. Truncated trk $\mathrm{C}$ expression inhibits full-length trk $\mathrm{C}$ activation. Native packaging cells or packaging cells expressing truncated trk $\mathrm{C}$ were transfected with full-length trk C, and cells were untreated $(-)$ or treated $(+)$ with $50 \mathrm{ng} / \mathrm{ml} \mathrm{NT}-3$ for $5 \mathrm{~min}$. $A$, Truncated trk C expression was detected in cell lysates by Western blot analysis using antisera ( $\alpha$-trunc $C$ ) that specifically recognized the truncated trk $C$ receptor. $B$, Full-length trk $\mathrm{C}$ expression was confirmed by immunoprecipitation of cell lysates with antisera $(\alpha-F L$ trk $)$ that recognized full-length trk $\mathrm{C}$, after which Western blots were probed with the same antisera. $C$, To detect phosphorylation of trk $\mathrm{C}$ receptors, cell lysates were immunoprecipitated with antisera $(\alpha$-FLtrk) that recognized full-length trk C, after which Western blots were probed with an antiphosphotyrosine antibody $(\alpha-P Y)$. Only cells that expressed full-length trk $\mathrm{C}$ alone without the expression of truncated trk $\mathrm{C}$ demonstrated a robust ligand-induced signal for trk $\mathrm{C}$ receptor phosphorylation. Western blot analysis of lysates from cells overexpressing trk A (615) were probed with $\alpha$-FLtrk $(B)$ and $\alpha$-PY $(C)$, which served as positive controls for trk expression $(B)$ and trk phosphorylation $(C)$.

are transcribed as a dicistronic message separated by an IRES sequence. Because the protein expression of $\beta$-galactosidase, translated in a 5' cap independent manner via the IRES element, serves as the marker for truncated trk $\mathrm{C}$ expression by virally infected cells, double immunofluorescent labeling of cells was performed to assess the coordinate expression of truncated trk $\mathrm{C}$ and $\beta$-galactosidase. Sections of E7 chick retinas, obtained after infection at E2.5 with the truncated trk $\mathrm{C} / \beta$-galactosidaseencoding virus, demonstrated that truncated trk $C$ labeling coincides with staining for the reporter gene, $\beta$-galactosidase (Fig. 4). Immunodetection of truncated trk $C$ expression appeared to be limited to cells expressing $\beta$-galactosidase, suggesting that the level of expression of endogenous truncated trk $C$ receptor at this stage of retinal development is low.

\section{Expression of truncated trk $\mathbf{C}$ reduces clone size}

To assess the effects of truncated trk $\mathrm{C}$ expression on retinal clone size, embryos were injected subretinally at E2.5 with retrovirus encoding truncated trk $\mathrm{C} / \mathrm{lacZ}$ or lacZ alone at low viral titers $\left(10^{5}-10^{6}\right.$ virions $\left./ \mathrm{ml}\right)$ to obtain spatially isolated colonies of cells at E15 as visualized by X-gal histochemistry. In previous lineage analysis studies in chick retina, such viral titers similarly produced isolated clones of cells (Fekete et al., 1994), consistent with our findings. In our experiments, we observed on average two to three 

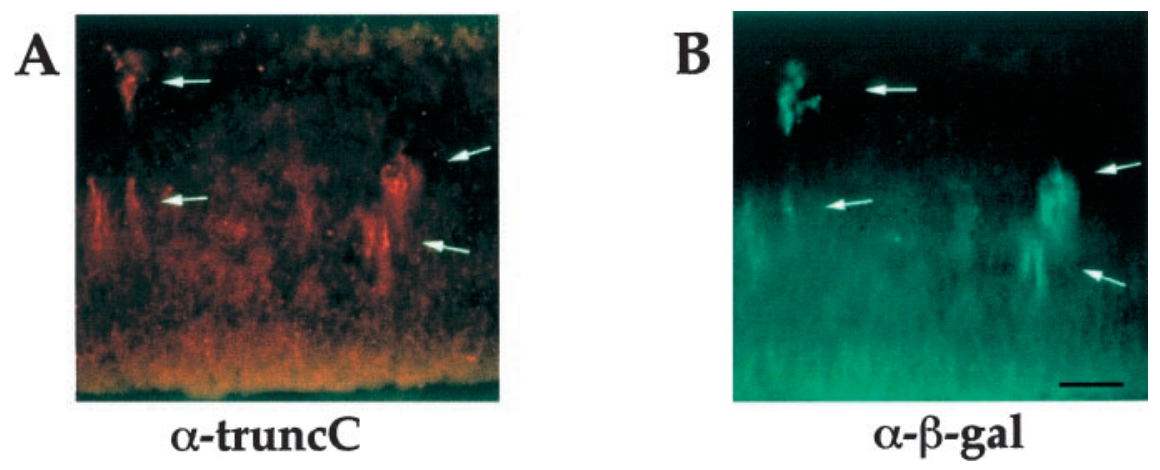

Figure 4. Expression of virally transduced truncated trk $\mathrm{C}$ in $\mathrm{E} 7$ chick retina after infection with retroviral vector encoding truncated trk C and the reporter gene $\beta$-gal. Immunofluorescence double labeling was performed using a polyclonal antibody to truncated trk $C$ followed by a Texas Red-conjugated secondary antibody $(A)$ in combination with a monoclonal antibody to $\beta$-gal and fluorescein-labeled secondary antibody $(B)$. $A$ and $B$ are of the same field. Coexpression is evident in what appear to be the elongated progenitor cells that populate the compacted retinal neuroepithelium at this developmental age (arrows). Sections stained with only one primary and secondary antibody exhibited no signal in the other channel, indicating the absence of cross-contamination of signal. Scale bar, $20 \mu \mathrm{m}$.

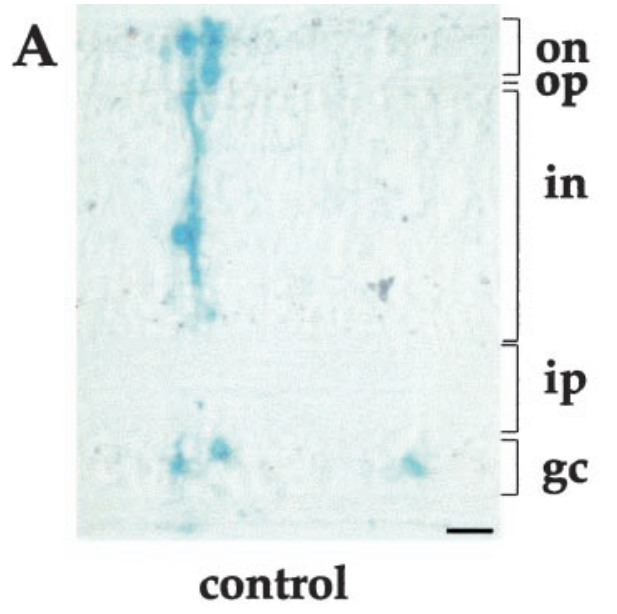

infective events (clones) within central retina after injection with either the control or truncated trk $\mathrm{C}$ virus.

Sections from E15 retinal clones infected with control lacZ virus exhibited multiple radial columns of $\beta$-gal-positive cells spanning the width of the retina, as shown previously (Fekete et al., 1994). Variable numbers of labeled single cells were also scattered throughout each retinal section (Fig. $5 A$ ). In contrast, in sections from truncated trk C-infected clones harvested at E15, radial arrays were also observed, but more often with fewer cells present in each column. Consequently, there appeared to be a greater frequency of single isolated cells (Fig. $5 B$ ). Nevertheless, $\beta$-gal-positive cells were detected in all cellular laminae in the truncated trk C-expressing clones.

Chick retinal progenitors normally undergo lateral mixing along the neuroepithelium before they migrate radially and differentiate into columnar arrays (Fekete et al., 1994). To determine whether the extent of lateral migration was affected by overexpression of truncated trk $\mathrm{C}$, the total area that a clone encompassed in retina was determined by calculating the greatest distance between transgene-expressing cells in serial sections of a clone. No difference between truncated trk C-expressing and control clones was detected (data not shown), suggesting that the lateral migration of cells within retina was not impaired by altered NT-3 signaling. Additionally, after analysis of retinas injected at high viral titers with the truncated trk $\mathrm{C}$ or control virus, there were no differences in the ability of virally infected cells to migrate to different retinal layers (data not shown).
Figure 5. Central clones in E15 chick retina. $\beta$-gal expression is detected in clones after infection at E2.5-E3 with control retrovirus transducing only lacZ $(A)$ or retrovirus transducing both truncated trk $\mathrm{C}$ and lacZ $(B)$. Clones were located in central retina. In control clones, $\beta$-gal-positive cells were arranged predominantly in radial arrays. Truncated trk $\mathrm{C}$-expressing clones consisted of fewer radial arrays, and more isolated $\beta$-gal-positive cells were observed. $g c$, Ganglion cell layer; i $p$, inner plexiform layer; in, inner nuclear layer; $o p$, outer plexiform layer; on, outer nuclear layer. Scale bar, $10 \mu \mathrm{m}$.

\section{truncC}

The sizes of the retrovirally infected E15 clones were determined by counting $\beta$-gal-positive cells on serial sections of retina from six truncated trk $\mathrm{C}$ clones and three control clones obtained from individual embryos. The sizes of the three control clones fell within the range of clone sizes found within central retina in

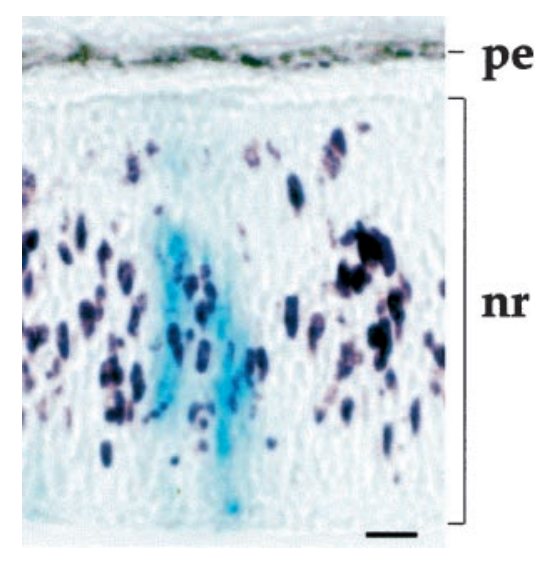

Figure 8. BrdU labeling in E6 retina expressing the $\beta$-galactosidase transgene. Retinas that were infected at E2.5-E3 with retroviral vector were administered BrdU at E6 for $4 \mathrm{hr}$ before they were killed. BrdU histochemistry was performed on X-gal-stained sections. BrdU-labeled nuclei (purple) were counted in $\beta$-gal-positive areas and in flanking uninfected ( $\beta$-gal-negative) areas that served as an internal control. pe, Pigmented epithelium; $n r$, neural retina. Scale bar, $10 \mu \mathrm{m}$. 


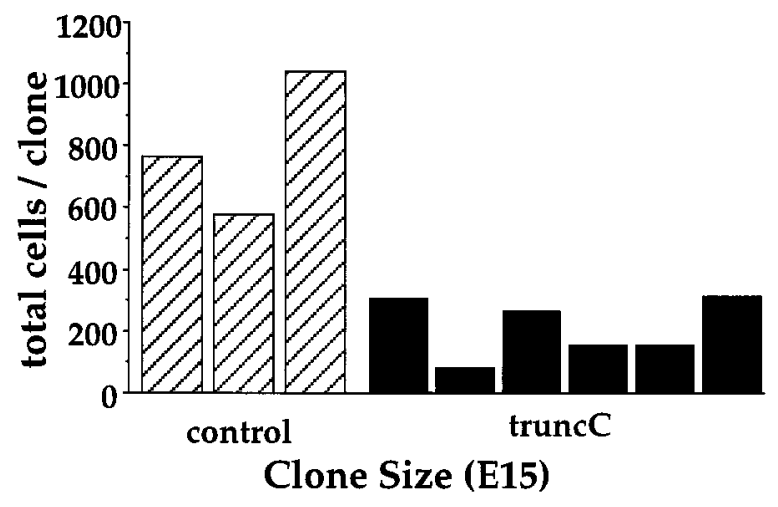

Figure 6. Effects of overexpression of truncated trk $\mathrm{C}$ on clone size in central retina at E15. Retinas were infected at E2.5-E3 with retroviral vector encoding truncated trk $\mathrm{C}$ and $\beta$-gal or $\beta$-gal only (control). Truncated trk $\mathrm{C}$-expressing clones were composed of fewer cell numbers compared with control-infected clones. Each bar represents the total number of cells from an individual clone. The mean of the six truncated trk $\mathrm{C}$ values was significantly different than the mean of the three control values, $p<0.01$; unpaired two-tailed $t$ test.

previous chick lineage studies (Fekete et al., 1994). Clones expressing truncated trk $\mathrm{C}$ consistently had fewer cells per clone compared with control CXL-infected clones $(p<0.01$; unpaired two-tailed $t$ test) (Fig. 6). Overall, a 72\% decrease in total cell number was observed in clones in which trk $\mathrm{C}$ signaling was disrupted, suggesting that NT-3 functions to regulate clone size in the developing chick retina.

Because overexpression of truncated trk $\mathrm{C}$ led to an alteration in retinal clone size at E15, we sought to determine whether NT-3 regulates clonal cell numbers at earlier stages of retinal development by analyzing clones at E9. At this stage, progenitor cells are proliferating, and many cells are undifferentiated. However, migrating cells in the retinal neuroepithelium are elongated and densely packed at E9, precluding accurate counting of individual $\beta$-gal-labeled cells. Therefore, clone size at E9 was quantified on the basis of clonal volume (see Materials and Methods). The validity of this method was demonstrated by selecting one control and one truncated trk C-expressing clone from E15 retinae for clonal volume measurements. The clone volumes were calculated to be 705 and $202 \mathrm{~mm}^{2}$ (control and truncated trk C, respectively), a ratio of $3.5: 1$. The latter compares favorably to the 3.8:1 ratio obtained when clone size was determined by total cell number. Thus, clone volume measurements were considered to be a reliable measure of clone size.

Clone volumes from three truncated trk $\mathrm{C}$ and three control clones, each taken from individual embryos harvested at E9, revealed that the truncated trk $\mathrm{C}$-expressing clones were reduced in size relative to control clones ( $p<0.05$; unpaired two-tailed $t$ test) (Fig. 7). Indeed, the average reduction in clone size at E9 $(64 \%)$ was similar to the reduction in clone size observed at E15 (72\%), indicating that NT-3-mediated trk C signaling serves to regulate retinal cell numbers early in development.

\section{Expression of truncated trk $\mathbf{C}$ reduces cell proliferation}

The reduction in the size of truncated trk $\mathrm{C}$-expressing clones suggests that NT-3-mediated trk C signaling could induce proliferation of progenitor cells or inhibit apoptosis. To determine whether a dominant effect of NT-3 is to regulate cellular proliferation, BrdU incorporation was determined in control and truncated trk C-expressing clones that were position-matched within

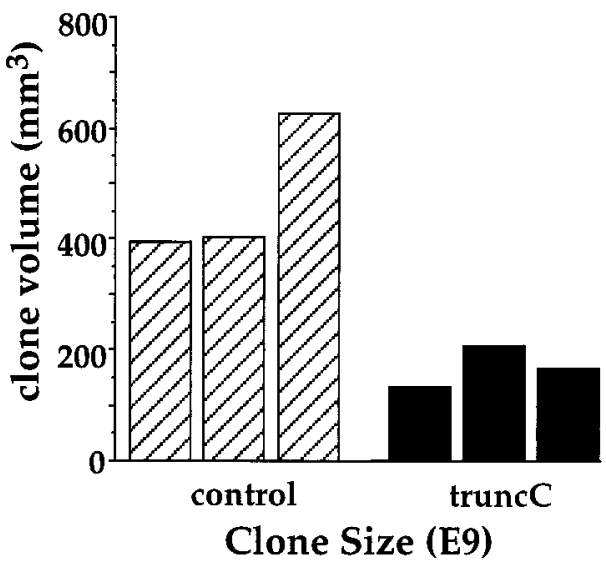

Figure 7. Effects of overexpression of truncated trk $\mathrm{C}$ on clone size in central retina at E9 on total cell volume $\left(\mathrm{mm}^{3}\right)$ per clone. Retinas were infected at E2.5-E3 with retroviral vector encoding truncated trk $\mathrm{C}$ and $\beta$-gal or $\beta$-gal only (control). Clonal volume in the truncated trk $\mathrm{C}$-expressing clones was reduced as compared with that in control clones. Each bar represents data from an individual clone. The mean of the three truncated trk $\mathrm{C}$ values was significantly different than the mean of the three control values, $p<0.05$; unpaired two-tailed $t$ test.

\begin{tabular}{|c|c|c|c|c|}
\hline \multirow[b]{2}{*}{ Embryo } & \multicolumn{2}{|c|}{ Truncated trk $\mathrm{C}$ expressing } & \multicolumn{2}{|l|}{ Control $^{a}$} \\
\hline & $\begin{array}{l}\text { Per } \mathrm{mm}^{2} \text { of } \\
\beta \text {-gal } \\
\text { area }\end{array}$ & $\begin{array}{l}\text { Per } \mathrm{mm}^{2} \text { of } \\
\beta-\mathrm{gal}^{-} \text {area }^{b}\end{array}$ & $\begin{array}{l}\text { Per } \mathrm{mm}^{2} \text { of } \\
\beta \text {-gal } \\
\text { area }\end{array}$ & $\begin{array}{l}\text { Per } \mathrm{mm}^{2} \text { of } \\
\beta \text {-gal }^{-} \text {area }^{b}\end{array}$ \\
\hline 1 & 11.40 & 19.88 & 12.43 & 13.46 \\
\hline 2 & 5.32 & 9.41 & 13.55 & 14.00 \\
\hline 3 & 7.64 & 15.95 & 15.47 & 14.63 \\
\hline 4 & 7.85 & 15.29 & 9.17 & 10.06 \\
\hline
\end{tabular}

The total numbers of BrdU-labeled nuclei per $\mathrm{mm}^{2}$ of retina at E6 were calculated from $\beta$-gal-positive areas that were position-matched within central retina of individual embryos. Retinas were infected at E2.5 with virus encoding either truncated trk $\mathrm{C}$ and $\beta$-gal or $\beta$-gal alone.

${ }^{a}$ Embryos injected with virus expressing lac $\mathrm{Z}$ only.

${ }^{b} \mathrm{BrdU}$ counts were performed in areas flanking $\beta$-gal ${ }^{+}$regions.

central retina. BrdU labeling of embryos was performed for $4 \mathrm{hr}$ at E6 (Fig. 8), and the numbers of BrdU ${ }^{+}$nuclei per unit $\left(\mathrm{mm}^{2}\right)$ area were assessed (Table 1) (see Materials and Methods). Quantitation of $\mathrm{BrdU}^{+}$cells within the $\beta$-gal-positive areas yielded a nearly $50 \%$ reduction in the relative numbers of BrdU-labeled nuclei in truncated trk $\mathrm{C}$-infected retinas as compared with control retinas (Fig. 9) $(p<0.005$; unpaired two-tailed $t$ test). This decrease is comparable to the observed reduction in clone size and suggests that an important function of NT-3 in early retinal neurogenesis is to regulate cell proliferation.

\section{Expression of truncated trk $\mathbf{C}$ reduces all retinal cell types}

To determine whether NT-3/trk C signaling regulates the differentiation of distinct cell types within the developing retina, clones in E15 retinas were also analyzed for cell type composition. In control experiments, immunohistochemical labeling was performed with cell type-specific markers to confirm the laminar positions of the retinal cell types. Using this positional information and morphological cues, the cell types were identified and counted within clones. Expression of truncated trk $\mathrm{C}$ resulted in a reduction in all major retinal cell types examined at E15 as 


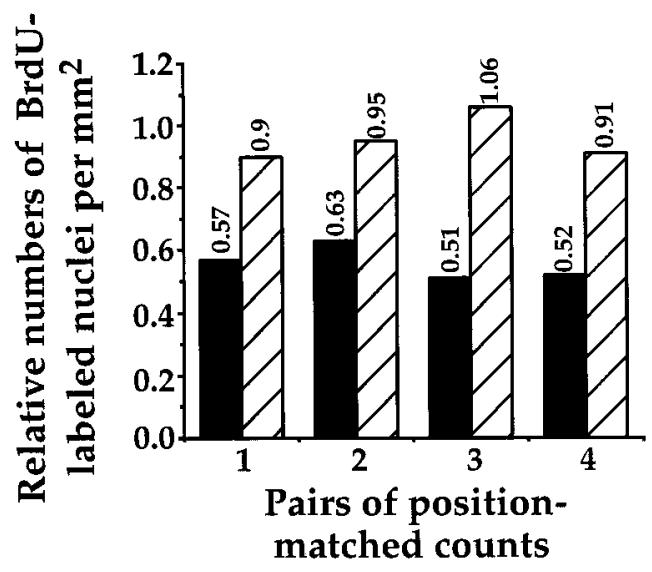

Figure 9. Effects of the overexpression of truncated trk $\mathrm{C}$ on proliferation of retinal progenitor cells. The relative numbers of BrdU-labeled nuclei per $\mathrm{mm}^{2}$ of retina at E6 were calculated after retinas were infected at E2.5 with virus encoding either truncated trk $\mathrm{C}$ and $\beta$-gal (solid bars) or $\beta$-gal alone (hatched bars). Relative numbers were calculated as the number of BrdU-labeled nuclei per $\mathrm{mm}^{2}$ of the $\beta$-gal-positive area versus the number in the adjacent $\beta$-gal-negative area (see Materials and Methods). Each bar represents data from a single retina. BrdU counts presented as pairs were obtained from $\beta$-gal-positive areas that were position-matched within central retina. The mean of paired differences between control and truncated trk $\mathrm{C}$ values was significant, $p<0.005$; paired two-tailed $t$ test.

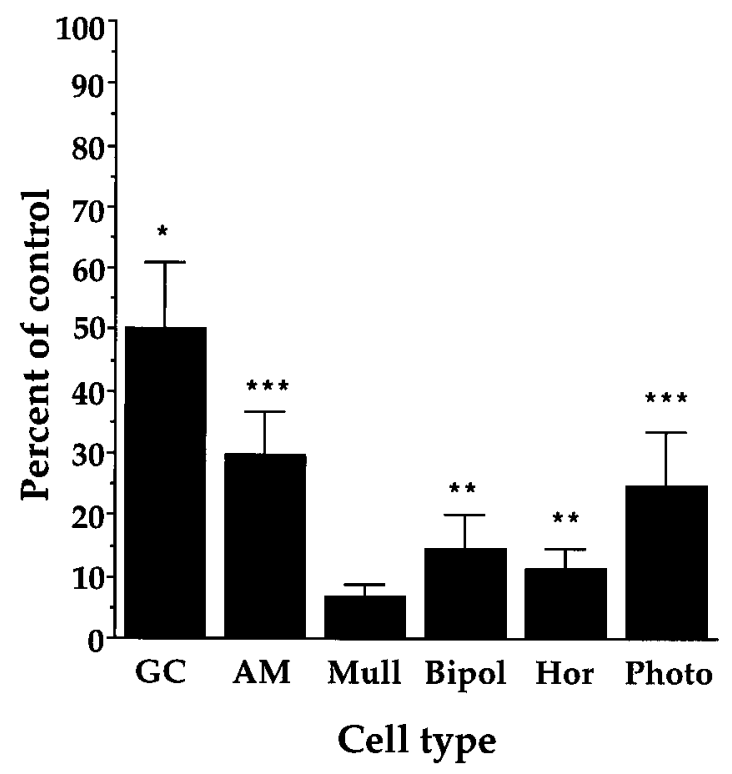

Figure 10. Effects of overexpression of truncated trk C on cell-type composition of clones in E15 chick retina. Retina were infected at E2.5-E3 with retroviral vector encoding truncated trk $\mathrm{C}$ and $\beta$-gal or $\beta$-gal only. Counts of different cell types were performed on the same clones (6 truncated trk C; 3 control) as are presented in Figure 5. Values are presented for each cell type in the truncated trk $\mathrm{C}$-expressing clones as mean percentage of control values \pm SEM. All cell types exhibited a reduction in cell number in the truncated trk $\mathrm{C}$-expressing retinas. ${ }^{*} p<$ $0.05 ; * * p<0.01 ; * * * p<0.001$; ANOVA and Newman-Keuls multiple comparisons post test. GC, Ganglion; AM, amacrine; Mull, Muller; Bipol, bipolar; Hor, horizontal; Photo, photoreceptor cells.

compared with control clones (Fig. 10). This decrease suggests that NT-3 may act on multipotent precursor cells in the early retina and concurs with our observation that truncated trk $\mathrm{C}$ expression reduces the numbers of BrdU-labeled nuclei of early retinal progenitors. This interpretation is also consistent with the observation that ganglion cells, which are born between E2 and E7 and are the first retinal cell type to become postmitotic (10\% are postmitotic by E3) (Prada et al., 1991), are the most modestly affected cell type in the truncated trk C-expressing clones (Fig. 10). Although injections were performed at E2.5, viral integration would not have occurred for at least $1 \mathrm{~d}$ (Fekete et al., 1994). This would result in a delay that might allow some ganglion cells to be born before the expression of the truncated trk $\mathrm{C}$ transgene.

\section{DISCUSSION}

\section{NT-3 is an early retinal mitogen}

By using retroviral gene delivery to inhibit NT-3-dependent trk C signaling, our studies reveal that NT-3 is a potent physiological mitogen in the early chick retina. This conclusion is supported by expression studies that demonstrate localization of both NT-3 and kinase-active trk $\mathrm{C}$ in neuroblastic regions of retina during the interval when progenitor cells are dividing. Additionally, the consistent reduction in the generation of six distinct retinal cell types suggests that NT-3-mediated activation of trk C promotes the proliferation of uncommitted neuroepithelial cells within the early retina. However, there may be additional factors that regulate progenitor cell proliferation, because inhibition of NT-3 signaling results in a $\sim 50 \%$ reduction in cell proliferation as assessed by BrdU incorporation. Indeed, in vitro studies reveal that retinal progenitors may change in their responsiveness to mitogenic signals during development and that growth factors may act in combination at different developmental stages (Lillien and Cepko, 1992; Anchan and Reh, 1995). In this regard, previous in vitro studies indicated that IGF-1 also acts as a retinal mitogen in chick (Hernandez-Sanchez et al., 1995). However, the actions of IGF-1 may be distinct from NT-3 because IGF-1 is expressed at low levels in retina until E9 and may affect only a subpopulation of retinal neuroepithelial cells (de la Rosa et al., 1994b; Hernandez-Sanchez et al., 1995; Frade et al., 1996). Thus, it will be important in future studies to determine whether NT-3 and IGF-1 act in a sequential and/or complementary manner on all or on specific subsets of progenitor cells to contribute to the generation of the retinal progenitor pool.

Analysis of E15 retinal clones expressing truncated trk $\mathrm{C}$ reveals a decrease in clone size that is represented in all the retinal cell types, suggesting that NT-3 can act early on uncommitted precursor cells. This decrease in clone size is consistent with previous studies in which the retinal laminae were thinner in embryos subjected to NT-3 depletion (Bovolenta et al., 1996). Because retinal progenitor cells change in their competence to respond to the environmental cues that promote differentiation, the numbers of available precursor cells at each stage of development will influence the ultimate number of each cell type that is generated. Therefore, the relative decrease observed in all of the cell types within the truncated trk $\mathrm{C}$ clones suggests that relatively fewer precursor cells reach each competent stage. This may also explain the phenotype observed on E15 sections, wherein truncated trk $\mathrm{C}$-expressing clones are composed of fewer complete radial columns of cells. The rate of neurogenesis is very rapid in early chick retina, with proliferating cells exhibiting short cycling times (7-10 hr) (Morris and Cowan, 1995). Therefore, even a modest inhibition in proliferation may significantly reduce the number of retinal precursor cells that are generated.

One mechanism to account for the observed decrease in cell proliferation upon inhibition of NT-3 signaling is by a slowing of the cell cycle progression. NT-3 has been demonstrated to be 
important in promoting oligodendroglial progenitor cells into S-phase entry as confirmed by the expression of c-myc and cdc2, which are proteins activated in the G1 and S phases of the cell cycle (Kumar et al., 1998). Therefore, blockade of NT-3 signaling by truncated trk $\mathrm{C}$ may act to inhibit the transition into $\mathrm{S}$ phase and consequently lengthen cell cycle times. The prolongation of cell cycle when NT-3 and trk C signaling are impaired may explain the results of previous experiments in which an expanded radial proliferative zone spanning the entire thickness of the inner nuclear layer is observed at E9 in those retinas treated at E3 with blocking antibodies to NT-3 (Bovolenta et al., 1996). Cell cycle times may be lengthened by a deficiency of NT-3 such that retinal progenitor cells remain in an expanded germinal zone for longer periods of time.

\section{Multiple roles for NT-3 during retinal development}

Although we have demonstrated that NT-3 is an early retinal mitogen, we cannot exclude additional trophic functions for NT-3 in later retinal development. Such pleiotropic roles for NT-3 have been observed in oligodendrocytes, in which NT-3 can promote either proliferation or survival depending on the stage of oligodendrocyte maturation (Cohen et al., 1996). In the retina, NT-3 may regulate trophic responses at later developmental stages, as has been suggested from in vitro experiments in which NT-3 promoted the survival of postmitotic ganglion cells and amacrine cells after E9 (de la Rosa et al., 1994a). Indeed, late trophic effects of NT-3 may help to explain the difference observed in the reduced numbers of $\mathrm{BrdU}^{+}$cells in truncated trk $\mathrm{C}$-expressing cells at E6 (50\%), which was less than that predicted by analyzing clone size at E15 in the truncated trk C clones (72\%). The larger decrease in cell numbers at E15 may be caused by truncated trk C inhibition of NT-3-mediated survival. Alternatively, after E6, NT-3 may continue to be an important mitogen until the end of neurogenesis at E12, such that the decrease in clone size observed at E15 may reflect the cumulative effects of inhibition of NT-3mediated proliferation caused by truncated trk $\mathrm{C}$ expression. Our studies also do not rigorously exclude trophic effects of NT-3 on ganglion cells, a role suggested by previous in vivo studies in which reduced numbers of ganglion cells were observed in embryos exposed to anti-NT-3 antisera (Bovolenta et al., 1996). However, these previous studies did not examine the effects of NT-3 depletion on other retinal cell types. Our studies also demonstrate a decrease in ganglion cell numbers at E15 in the truncated trk $\mathrm{C}$-expressing clones compared with control. However, a comparable decrease is observed for all of the other retinal cell types examined, which we attribute to effects of NT-3 on the proliferation of progenitor cells. One strength of the clonal analysis technique is that direct actions of NT-3/trk C signaling can be deduced in the context of normal expression of trk $\mathrm{C}$ in neighboring retina. This is distinctive from approaches using gene targeting or the addition of neutralizing antibodies to whole embryos, in which both direct and indirect actions of altered NT-3 signaling may be observed. Therefore, this approach allows the extension and redefinition of the actions of NT-3 as an important mitogen during early retinal development.

\section{Roles for endogenous truncated trk C}

Although we have demonstrated that overexpression of truncated trk C can inhibit NT-3-dependent signaling of kinase-active trk C in vitro, additional roles for the endogenous truncated trk $\mathrm{C}$ receptor have been postulated. For example, the truncated trk B receptor may regulate ganglion cell death in the developing rat retina, because expression of both truncated and full-length trk B transcripts has been detected in a subset of ganglion cells (Suzuki et al., 1998). Because the period of apoptosis in rat ganglion cells (E20-P7) parallels expression of truncated trk B in GCs (E19 to adult), Suzuki et al. (1998) suggested that endogenous truncated trk B expression may limit trk B signaling and hence regulate GC survival. Similarly, one can postulate from our results that the regulated expression of endogenous truncated trk $\mathrm{C}$ can restrict the number of progenitor cells generated during development caused by inhibition of kinase-active trk $\mathrm{C}$ signaling. Interestingly, alternative roles of truncated trk $\mathrm{C}$ that are independent of full-length trk $\mathrm{C}$ have been postulated during neural crest development (Hapner et al., 1998). It is important to recognize, however, that the phenotype of transgenic animals overexpressing truncated trk $\mathrm{C}$ recapitulates the phenotype of trk C and NT-3 null mutant animals (Palko et al., 1999), indicating that a dominant function of truncated trk $\mathrm{C}$, when coexpressed with kinaseactive trk $\mathrm{C}$, is to limit NT-3-mediated signaling.

A critical determinant of NT-3 actions during retinal development, therefore, appears to be based on the regulated expression of the trk $\mathrm{C}$ isoforms. Cross-linking analysis in several species reveals that the expression of the kinase-active trk $\mathrm{C}$ generally precedes the expression of truncated trk C (Allendoerfer et al., 1994; Escandon et al., 1994). The relative levels of expression of truncated trk $\mathrm{C}$ to kinase-active trk $\mathrm{C}$ within a cell might determine whether a cell will proliferate and advance to a postmitotic state or fail to respond to NT-3. As is the case with trk B, a critical ratio between the truncated and kinase-active trk $\mathrm{B}$ receptors may be necessary to impair kinase-active trk B signaling (Eide et al., 1996). Future studies will be necessary to determine the patterns of trk isoform switching to more clearly understand neurotrophin functions during development.

In conclusion, these studies suggest that endogenous NT-3 is an important mitogen in early retinal development and serves to establish the size of the progenitor pool from which all future differentiated cells arise. These studies define a novel action of NT-3, in addition to its characteristic functions of providing trophic support for specific retinal cell types during later stages of retinal development.

\section{REFERENCES}

Allendoerfer KL, Cabelli RJ, Escandon E, Kaplan DR, Nikolics K, Shatz CJ (1994) Regulation of neurotrophin receptors during the maturation of the mammalian visual system. J Neurosci 14:1795-1811.

Anchan RM, Reh TA (1995) Transforming growth factor-beta-3 is mitogenic for rat retinal progenitor cells in vitro. J Neurobiol 28:133-145.

Anchan RM, Reh TA, Angello J, Balliet A, Walker M (1991) EGF and TGF-alpha stimulate retinal neuroepithelial cell proliferation in vitro. Neuron 6:923-936.

Biffo S, Offenhauser N, Carter BD, Barde YA (1995) Selective binding and internalisation by truncated receptors restrict the availability of BDNF during development. Development 121:2461-2470.

Boucher SE, Hitchcock PF (1998) Insulin-related growth factors stimulate proliferation of retinal progenitors in the goldfish. J Comp Neurol 394:386-394.

Bovolenta P, Frade J-M, Marti E, Rodriguez-Pena M-A, Barde Y-A, Rodriguez-Tebar A (1996) Neurotrophin-3 antibodies disrupt the normal development of the chick retina. J Neurosci 16:4402-4410.

Cepko CL, Austin CP, Yang X, Alexiades M, Ezzeddine D (1996) Cell fate determination in the vertebrate retina. Proc Natl Acad Sci USA 93:589-595.

Chomczynski P, Sacchi N (1987) Single-step method of RNA isolation by acid guanidinium thiocyanate-phenol-chloroform extraction. Anal Biochem 162:156-159.

Cohen RI, Marmur R, Norton WT, Mehler MF, Kessler JA (1996) Nerve growth factor and neurotrophin-3 differentially regulate the 
proliferation and survival of developing rat brain oligodendrocytes. J Neurosci 16:6433-6442.

Das I, Hempstead BL, MacLeish PR, Sparrow JR (1997) Immunohistochemical analysis of the neurotrophins BDNF and NT-3 and their receptors trk $\mathrm{B}$, trk $\mathrm{C}$, and $\mathrm{p} 75$ in the developing chick retina. Vis Neurosci 14:835-842.

Davies AM (1994) The role of neurotrophins in the developing nervous system. J Neurobiol 25:1134-1348.

de la Rosa EJ, Arribas A, Frade JM, Rodriguez-Tebar A (1994a) Role of neurotrophins in the control of neural development: neurotrophin-3 promotes both neuron differentiation and survival of cultured chick retinal cells. Neuroscience 58:347-352.

de la Rosa EJ, Bondy CA, Hernandez-Sanchez C, Wu X, Zhou J, Lopez-Carranza A, Scavo LM, de Pablo F (1994b) Insulin and insulin-like growth factor system components gene expression in the chicken retina from early neurogenesis until late development and their effect on neuroepithelial cells. Eur J Neurosci 6:1801-1810.

Donovan MJ, Miranda RC, Kraemer R, McCaffrey TA, Tessarollo L, Mahadeo D, Sharif S, Kaplan DR, Tsoulfas P, Parada L, Dominique Toran-Allerand C, Hajjar DP, Hempstead BL (1995) Neurotrophin and neurotrophin receptors in vascular smooth muscle cells. Am J Pathol 147:309-324.

Eide FF, Vining ER, Eide BL, Zang K, Wang X-Y, Reichardt LF (1996) Naturally occurring truncated trkB receptors have dominant inhibitory effects on brain-derived neurotrophic factor signaling. J Neurosci 16:3123-3129.

Escandon E, Soppet D, Rosenthal A, Mendoza-Ramirez J-L, Szonyi E, Burton LE, Henderson CE, Parada LF, Nikolics K (1994) Regulation of neurotrophin receptor expression during embryonic and postnatal development. J Neurosci 14:2054-2068.

Fekete DM, Perez-Miguelsanz J, Ryder EF, Cepko CL (1994) Clonal analysis in the chicken retina reveals tangential dispersion of clonally related cells. Dev Biol 166:666-682.

Fisher LJ (1979) Development of synaptic arrays in the inner plexiform layer of neonatal mouse retina. J Comp Neurol 187:359-372.

Frade JM, Marti E, Bovolenta P, Rodriguez-Pena MA, Perez-Garcia D, Rohrer H, Edgar D, Rodriguez-Tebar A (1996) Insulin-like growth factor-I stimulates neurogenesis in chick retina by regulating expression of the alpha 6 integrin subunit. Development 122:2497-2506.

Garner AS, Large TH (1994) Isoforms of the avian trkC receptor: a novel kinase insertion dissociates transformation and process outgrowth from survival. Neuron 13:457-472.

Hallbook F, Backstrom A, Kullander K, Ebendal T, Carri NG (1996) Expression of neurotrophins and trks receptors in the avian retina. J Comp Neurol 364:664-676.

Hamburger V, Hamilton HL (1992) A series of normal stages in the development of the chick embryo. Dev Dyn 195:231-272.

Hapner SJ, Boeshore KL, Large TH, Lefcort F (1998) Neural differentiation promoted by truncated trkC receptors in collaboration with p75(NTR). Dev Biol 201:90-100.

Hempstead BL, Schleifer LS, Chao MV (1989) Expression of functional nerve growth factor receptors after gene transfer. Science 243:373-375.

Hempstead BL, Martin-Zanca D, Kaplan DR, Parada LF, Chao MV (1991) High-affinity NGF binding requires coexpression of the trk protooncogene and the ow-affinity NGF receptor. Nature 350:678-683.

Hempstead BL, Rabin SJ, Kaplan L, Reid S, Parada LF, Kaplan DR (1992) Overexpression of the trk tyrosine kinase rapidly accelerates nerve growth factor-induced differentiation. Neuron 9:883-896.

Henion PD, Garner AS, Large TH, Weston JA (1995) trkC-mediated NT-3 signaling is required for the early development of a subpopulation of neurogenic neural crest cells. Dev Biol 172:602-613.

Hernandez-Sanchez C, Lopez-Carranza A, Alarcon C, de La Rosa EJ, de Pablo F (1995) Autocrine/paracrine role of insulin-related growth factors in neurogenesis: local expression and effects on cell proliferation and differentiation in retina. Proc Natl Acad Sci USA 92:9834-9838.
Herzog KH, von Bartheld CS (1998) Contributions of the optic tectum and the retina as sources of brain-derived neurotrophic factor for retinal ganglion cells in the chick embryo. J Neurosci 18:2891-2906.

Holt CE, Bertsch TW, Ellis HM, Harris WA (1988) Cellular determination in the Xenopus retina is independent of lineage and birth date. Neuron 1:15-26.

Kaplan DR, Hempstead BL, Martin-Zanca D, Chao MV, Parada LF (1991) The trk proto-oncogene product: a signal transducing receptor for nerve growth factor. Science 252:554-558.

Kumar S, Kahn MA, Dinh L, de Vellis J (1998) NT-3-mediated TrkC receptor activation promotes proliferation and cell survival of rodent progenitor oligodendrocyte cells in vitro and in vivo. J Neurosci Res 54:754-765.

Lewin GR, Barde YA (1996) Physiology of the neurotrophins. Annu Rev Neurosci 19:289-317.

Lillien L (1994) Neurogenesis in the vertebrate retina. Perspect Dev Neurobiol 2:175-182.

Lillien L, Cepko C (1992) Control of proliferation in the retina: temporal changes in responsiveness to FGF and TGF alpha. Development 115:253-266.

Menn B, Timsit S, Calothy G, Lamballe F (1998) Differential expression of TrkC catalytic and noncatalytic isoforms suggests that they act independently or in association. J Comp Neurol 401:47-64.

Mikawa T (1995) Retroviral targeting of FGF and FGFR in cardiomyocytes and coronary vascular cells during heart development. Ann NY Acad Sci 752:506-515.

Mikawa T, Fischman DA, Dougherty JP, Brown AMC (1991) In vivo analysis of a new lacZ retrovirus vector suitable for cell lineage marking in avian and other species. Exp Cell Res 195:516-523.

Morris VB, Cowan R (1995) An analysis of the growth of the retinal cell population in embryonic chicks yielding proliferative ratios, numbers of proliferative and non- proliferative cells and cell-cycle times for successive generations of cell cycles. Cell Prolif 28:373-391.

Palko ME, Coppola V, Tessarollo L (1999) Evidence for a role of truncated trkC receptor isoforms in mouse development. J Neurosci 19:775-782.

Prada C, Puga J, Perez-Mendez L, Lopez R, Ramirez G (1991) Spatial and temporal patterns of neurogenesis in the chick retina. Eur J Neurosci 3:559-569.

Suzuki A, Nomura S, Morii E, Fukuda Y, Kosaka J (1998) Localization of mRNAs for trkB isoforms and p75 in rat retinal ganglion cells. J Neurosci Res 54:27-37.

Tessarollo L, Tsoulfas P, Donovan MJ, Palko ME, Blair-Flynn J, Hempstead BL, Parada LF (1997) Targeted deletion of all isoforms of the trkC gene suggests the use of alternate receptors by its ligand neurotrophin-3 in neuronal development and implicates trkC in normal cardiogenesis. Proc Natl Acad Sci USA 94:14776-14781.

Tsoulfas P, Soppet D, Escandon E, Tessarollo L, Mendoza-Ramirez JL, Nikolics K, Parada LF (1993) The rat trkC locus encodes multiple neurogenic receptors that exhibit differential response to neurotrophin-3 in PC12 cells. Neuron 10:975-990.

Turner DL, Snyder EY, Cepko CL (1990) Lineage-independent determination of cell type in the embryonic mouse retina. Neuron 4:833-845.

Valenzuela DM, Maisonpierre PC, Glass DJ, Rojas E, Nunez L, Kong Y, Gies DR, Stitt TN, Ip NY, Yancopoulos GD (1993) Alternative forms of rat TrkC with different functional capabilities. Neuron 10:963-974.

von Bartheld CS, Williams R, Lefcort F, Clary DO, Reichardt LF, Bothwell M (1996a) Retrograde transport of neurotrophins from the eye to the brain in chick embryos: roles of the $\mathrm{p} 75^{\mathrm{NTR}}$ and trkB receptors. J Neurosci 16:2995-3008.

von Bartheld CS, Byers MR, Williams R, Bothwell M (1996b) Anterograde transport of neurotrophins and axodendritic transfer in the developing visual system. Nature 379:830-833. 